\title{
SISTEM INFORMASI GEOGRAFI UNTUK ZONASI KERENTANAN KEBAKARAN LAHAN DAN HUTAN DI KECAMATAN MALIFUT, HALMAHERA UTARA
}

\author{
Sahrul S. Adam, Mohammad Gamal Rindarjono², Puguh Karyanto ${ }^{3}$ \\ ${ }^{1,2,3}$ Fakultas Keguruan dan Ilmu Pendidikan, Universitas Sebelas Maret \\ 1adamsahrul.edu@gmail.com, ${ }^{2}$ mas6amal@yahoo.com, ${ }^{3}$ karyarina@yahoo.com
}

(Naskah masuk: 20 Januari 2019, diterima untuk diterbitkan: 27 Mei 2019)

\begin{abstract}
Abstrak
Bencana kebakaran lahan dan hutan berperan penting secara ekologis menyebabkan kerusakan lahan dan hutan sebagai konsekuensi dari perubahan tutupan lahan dan efek yang terakumulasi dari gangguan antropogenik. Penelitian ini bertujuan untuk memetakan dan mengkaji kerentanan kebakaran lahan dan hutan di Kecamatan Malifut, Halmahera Utara. Metode yang digunakan adalah deskriptif. Pengolahan dan analisis data berbasis software Sistem Informasi Geografi yakni ArcGIS 10.1 dengan skoring dan overlay sebagai teknik analisis data. Hasil penelitian ini menunjukkan bahwa kelas kerentanan kebakaran lahan dan hutan di Kecamatan Malifut berada pada tiga kelas kerentanan, kelas kerentanan kebakaran rendah seluas 1,118.4 ha atau 3.18\%, meliputi jenis tutupan lahan hutan mangrove primer dan tanah terbuka. Kerentanan kebakaran lahan kelas sedang meliputi area seluas 13,601.9 ha atau 38.72\% yang sebagian besar terdapat di jenis tutupan lahan hutan produksi, serta diikuti pertanian lahan kering, hutan mangrove sekunder dan hutan lahan kering sekunder. Untuk kelas kerentanan kebakaran tinggi merupakan yang terluas mencakup area seluas 20,401.9 ha atau 58.08\%. Tutupan lahan dengan kelas kerentanan kebakaran tinggi sebagian besar berasal dari hutan lahan kering sekunder, pertanian lahan kering, hutan produksi, dan semak belukar.
\end{abstract}

Kata Kunci: SIG, kerentanan, kebakaran lahan dan hutan

\section{GEOGRAPHIC INFORMATION SYSTEM FOR VULNERABILITY ZONING OF LAND AND FOREST FIRE IN MALIFUT SUB-DISTRICT, NORTH HALMAHERA}

\begin{abstract}
Land and forest fires disasters played an important role ecologically causing the demage of land and forest as a consequence of change in land cover and accumulated effect antropogenic disorder. This researcher aimed to maping and assess the vulnerability of land and forest fire in Malifut Sub-district, North Halmahera. The research used descriptive method. Processing and analysis based on Geographic Information System software namely ArcGIS 10.1 and used scoring and overlay as data analysis techniques. The result of the research shown the class of vulnerability fire land and forest in Malifut Sub-district categorized into three classes, low vulnerability fire class of 1,118.4 hectares or 3.18\%, included covering land types of primary mangrove forest and open land. Moderate vulnerability fire land class covers an area of 13,601.9 hectares or 38.72\% most of which land cover by production forest, followed by dryland agriculture, secondary mangrove forest and secondary dryland forest. In higher vulnerability fire class was the widest area of 20,401.9 hectares or 58.08\%. Land cover with higher vulnerability class mostly found in secondary dryland forest, dryland agriculture, production forest, and shrubs.
\end{abstract}

Keywords: GIS, vulnerability, land and forest fire

\section{PENDAHULUAN (huruf besar, 10pt, tebal)}

Secara historis, kebakaran hutan dan lahan adalah fenomena yang terus berulang di semua wilayah berhutan di Indonesia. Data yang dikeluarkan oleh World Bank Group pada januari 2016 bahwa antara bulan Juni dan Oktober 2015 terdapat 2,6 juta hektar hutan dan lahan telah terbakar dengan kerugian diperkirakan mencapai USD 16,1 miliar (Glauber, 2016). Sletnes memberi gambaran lebih luas bahwa hutan dan lahan merupakan faktor ekonomi yang penting, dan pada saat bersamaan menyediakan barang dan jasa, ekosistem alami yang kompleks, dinamis, sangat berharga yang juga memfasilitasi dan melindungi keanekaragaman hayati (Sletnes, 2010).

Kebakaran hutan memiliki dampak cukup besar terhadap sistem hidrologi, degradasi lahan, banjir dan erosi tanah (Sugiarto, Gandasasmita, \& Lailan, 2013), hilangnya keanekaragaman hayati, hingga degradasi hutan dan lahan (Ajin, 2016). Hutan dan lahan bagi masyarakat yang berada dan bergantung pada hasil hutan menjadi lebih berefek seperti kawasan hutan 
yang rusak berat membutuhkan penanganan yang tidak sederhana, selain itu masyarakat yang kehilangan mata pencaharian memerlukan penanganan yang tak bisa ditunda (Siswoyo, 2007). Pada umumnya tidak ada defenisi tunggal kebakaran atau tingkat keparahan kebakaran, kedua istilah tersebut telah digunakan secara bergantian dalam literature (Mulder, 2009). Akar persoalan kebakaran lahan dan hutan menjadi semakin beragam mulai dari faktor alami hingga buatan manusia yang merambat pada perilaku sosial dan ekonomi serta faktor budaya. Bertolak dari pemahaman itulah konsep kerentanan menjadi fokus yang tak kalah penting untuk melihat lebih jauh berbagai macam penyebab bencana suatu kawasan.

\section{Kerentanan Kebakaran Lahan dan Hutan}

Kerentanan awal mulanya sering digunakan dalam berbagai literatur untuk menjelaskan adanya risiko, bahaya dan bencana, tetapi menjadi lebih menonjol di bidang perubahan iklim global dan studi lingkungan hingga pembangunan (Cutter S. L., 2013). Kerentanan sebagai faktor utama yang berpengaruh terhadap kerentanan terutama pada aspek sosial, antaranya, kurangnya akses ke sumber daya termasuk informasi, pengetahuan, teknologi, akses terbatas ke kekuatan dan keterwakilan politik, modal sosial, kepercayaan dan adat istiadat, individu lemah dan fisik yang terbatas serta jenis dan kerapatan infrastruktur (Cutter, 2003). Defenisi kerentanan sosial bagaimanapun terkadang memuat faktor ekonomi dan lingkungan, misalnya kerentanan disebabkan karena kemiskinan, ketersediaan cadangan sumber ekonomi, rentan karena faktor topografi dimana memaksa sumber daya manusia yang semakin banyak jika terjadi kebakaran di area pegunungan yang jauh dan luas. Artinya bahwa pada situasi tertentu konsep kerentanan sulit untuk dibatasi dan menjangkau kompleksitas dari setiap elemen sosial, ekonomi dan lingkungan secara bersamaan.

Kerentanan merupakan keterbatasan dalam merespon situasi karena kemungkinan masalah kesehatan, keterbatasan dukungan ekonomi, kurangnya akses ke sumber daya penting selama peristiwa bencana hingga respon untuk memulihkan diri dari situasi bencana (Garbutta, Ellulb, \& Fujiyamab, 2015). BAKORNAS PB mendefenisikan kerentanan sebagai sekumpulan kondisi dan atau suatu akibat faktor fisik, sosial, ekonomi dan lingkungan yang berpengaruh buruk terhadap upayaupaya pencegahan dan penanggulangan bencana (Hapsoro \& Buchori, 2015). Bagaimanapun, konsep kerentanan sangatlah kompleks, meliputi berbagai macam hal yang ada dalam satu ruang, baik dalam bentuk komunitas, pengetahuan, ekonomi, faktor fisik lingkungan, kesemuanya memiliki hubungan yang sangat kuat dalam memicu terjadinya kerentanan.

Beberapa indikator kerentanan yang ditemukan oleh Ersado (2006) dalam penelitiannya di Serbia, khususnya pada tataran keluarga diantaranya, kerentanan karena faktor geografi, karakteristik keluarga, rendahnya kepemilikan asset, penyimpangan cuaca dan iklim, dan kebijakan publik yang tidak memihak keluarga (Sugiharto, 2015). Pada kasus kerentanan karena faktor ekonomi, bahwa relasi antara kebakaran lahan dengan kekuatan ekonomi terlihat sangat kuat, dimana faktor kemiskinan menjadi persoalan utama yang mendorong masyarakat miskin membuka hutan dan lahan dengan cara membakar (Solichin, 2007). Mercer dan Prestemon menemukan hubungan positif antara kemiskinan dan luas lahan liar yang terbakar dan intensitas kebakaran di daratan liar, menunjukkan bahwa begitu kebakaran hutan liar dinyalakan, masyarakat miskin memiliki lebih sedikit sumber daya untuk memadamkan api (Gaither, 2011).

Kerentanan bencana kebakaran lahan dan hutan merupakan suatu situasi dimana kondisi fisik lingkungan menjadi faktor utama penyebab kebakaran. Misalnya kondisi tanah, dimana jenis tanah gambut lebih rentan terbakar, ritme musim kemarau yang berkepanjangan karena pengaruh fenomena el nino. El nino diakui menjadi penyumbang terbesar musim panas berkepanjangan yang juga meningkatkan kebakaran hutan dan lahan serta kekeringan tanaman pertanian antara 8 - 10 kali lipat (Sudibyakto, 2003). Kasus lainnya dalam konteks produktifitas hasil pertanian dimana tantangan musim kemarau merupakan masalah yang terus berulang menjadikannya sebagai indikator penting dalam mengantisipasi bencana kebakaran, iklim yang ekstrem menjadikan kawasan pertanian semakin rentan dan mendorong ketidakstabilan hasil produksi (Crowards, 2000). Selain itu, kondisi hutan dan lahan seperti kerapatan vegetasi dimana luasan dan kerapatan vegetasi tentu menjadi krusial dalam penilaian kerentanan sebab tipe umum kebakaran adalah kebakaran permukaan (surface fire) yang merambat pada lantai hutan dan kebakaran tajuk dan juga pada tumbuhan lebih tinggi antar tajuk yang kering (Bapeda Provinsi Yogyakarta, 2008), hingga kondisi topografi dan perilaku pemanfaatan atau pembukaan lahan.

\section{SIG dan Pemanfaatannya untuk Kajian Kerentanan Kebakaran Lahan dan Hutan}

Pada konteks kajian kerentanan kebakaran, pemanfatan Sistem Informasi Geografi (SIG) sudah digunakan untuk analisa dan pengamatan kebakaran hutan sejak tahun 1990-an. Fungsi dari SIG ini telah bisa digunakan untuk monitoring kebakaran dan membuat rencana antisipasi kebakaran dengan pembuatan peta rawan kebakaran melalui teknik pemodelan (Tarigan, 2016). Kemampuan SIG dalam strategi prediktif menjadikannya sangat handal dalam pemetaan sehingga dapat menghasilkan produk berupa peta kawasan yang rawan terbakar serta dapat digunakan untuk menghitung luasan areal yang terbakar dan strategi adaptasi penanganannya. 
Defenisi awal oleh Calkins dan Tomlinson (1977), SIG adalah paket perangkat lunak terintegrasi yang dirancang khusus untuk digunakan dengan data geografis yang melakukan serangkaian tugas penanganan data yang komprehensif (Weng, 2010). SIG merupakan sebuah sistem yang didesain untuk menangkap, menyimpan, memanipulasi, menganalisa, mengatur, dan menampilkan seluruh jenis data geografi (Rahayu, 2016). Pemanfaatan SIG merupakan terobosan besar dalam sejarah teknologi informasi. Pemanfaatan SIG menjadi handal sebab kemampuannya dalam menggabungkan berbagai sumber informasi untuk pemodelan atau pemetaan (Darmawan, 2001). SIG terdiri dari perangkat keras dan perangkat lunak komputer, data georeferensi pada atribut lingkungan hingga metadata (LaGro, 2005).

Prinsipnya, dengan aplikasi SIG, Anda dapat mengumpulkan data spasial, memasukkannya ke dalam sistem SIG, menyimpan untuk digunakan di masa depan dan melakukan analisis spasial untuk membuat peta/ grafik/ tabel yang dapat membantu keputusan spasial dengan tujuan untuk meningkatkan pembangunan pertanian (Bernard, 2017). SIG merupakan alat yang handal untuk menangani data spasial, dimana data dipelihara dalam bentuk digital sehingga data ini lebih padat dibanding dalam bentuk peta cetak, tabel, atau dalam bentuk konvensional lainya yang akhirnya akan mempercepat pekerjaan dan meringankan biaya yang diperlukan (Arifin, 2010).

Pemanfaatan SIG secara efektif, penting untuk memahami sifat dasar dan aplikasi setiap model data baik data raster dan vektor. Model data raster dirancang dengan fokus pada analisis, pemodelan, dan pemprosesan gambar (Neteler \& Mitasova, 2008). Ada 6 pemahaman dasar pemodelan spasial dalam SIG menurut Lo et al, yakni 1) menyatakan masalah, 2) memecah komponen masalah, 3) pencarian atau pengumpulan data, 4) pemilihan salah satu atau lebih model analisis spasial yang sesuai untuk digunakan, 5) pemilihan program SIG yang sesuai (model data vektor atau raster), dan 6) pelaksanaan atau implementasi model (Widodo, 2014).

Perangkat SIG yang digunakan dalam pengolahan data adalah software ArcGIS. ArcGIS menyediakan koleksi alat analitik yang kaya dan beragam untuk Anda manfaatkan dan terapkan pada pekerjaan dan masalah (ESRI, 2016). Model yang digunakan dalam pengolahan data yakni pemetaan dengan teknik skoring dan overlay dengan berbasis pada data raster dan vektor. Data vektor menggunakan serangkaian lokasi $\mathrm{x}-\mathrm{y}$ untuk menyimpan informasi berupa titik, garis, dan polygon yang termuat dalam shapefile yang dirancang dan diatur oleh ESRI, dan dimaksudkan untuk bekerja secara bergantian untuk mengkomunikasikan data antara ESRI dan produk perangkat lunak dan analisis SIG(Ahmed, dkk, 2018) Data vektor ini kemudian dikonversi kedalam bentuk raster agar bisa dikalkulasi dengan teknik skoring dan pembobotan.

Secara eksklusif, pemanfaatan SIG untuk pemetaan kerentanan kebakaran lahan dan hutan di kawasan Kecamatan Malifut belum dilakukan. Hal ini menjadi dasar penelitian ini. Tak lepas dari itu, desa tangguh bencana menjadi program mendasar jangka panjang pemerintah Republik Indonesia yang dimana masyarakat desa adalah yang paling dominan dalam menerima dampak bencana, khususnya masyarakat yang tinggal dikawasan hutan dengan mengandalkan kawasan hutan dan lahan sebagai kekuatan sentral ekonomi serta menjaga kerusakan hutan dan lahan. Dengan demikian, perlu dilakukan pemetaan serta mengkaji kawasan yang rentan kebakaran dimasa depan.

Tujuan penelitian ini adalah mengkaji kerentanan kebakaran lahan dan hutan di Kecamatan Malifut berdasarkan peta tutupan lahan, peta jenis tanah dan peta curah hujan melalui pemetaan berbasis software ArcGIS 10.1 dari Sistem Informasi Geografi. Hasil akhir dari tiap peta kemudian dioverlay (tumpang susun) untuk mendapatkan peta kerentanan yang merupakan generalisasi dari masingmasing peta dan akan digunakan untuk pengambilan keputusan.

\section{METODE PENELITIAN}

Wilayah penelitian terletak di kawasan hutan dan lahan Kecamatan Malifut yang secara administrasi berada di kawasan pemerintah Kabupaten Halmahera Utara, Provinsi Maluku Utara dengan luas total 35,991.81 hektar. Secara astronomis terletak pada kordinat $1^{\circ} 09^{\prime} 28.3^{\prime \prime} \mathrm{N}$ Lintang Utara dan 127047'19.5"E Bujur Timur. Penelitian ini menggunakan metode deskriptif dengan pendekatan survei untuk pengamatan wilayah penelitian dan pengumpulan data sekunder. Data sekunder diperoleh dari instansi pemerintahan berupa data spasial dan non spasial yang terdiri atas peta tutupan lahan, peta jenis tanah, peta kawasan administrasi kecamatan dan peta curah hujan tahun 2016 yang diterbitkan oleh Badan Perencanaan dan Pembangunan Daerah Kabupaten Halmahera Utara skala 1:250.000.

Teknik pengolahan dan analisis data berbasis pada perangkat Sistem Informasi Geografi yaitu software ArcGIS 10.1. Analisis dibagi dalam dua tahap pemodelan, yakni model skoring dan overlay. Model skoring merupakan tahap skoring dan pembobotan pada data raster, yang didalamnya terdapat proses operasi matematika sesuai parameter tiap kerentanan. Tahap overlay merupakan menggabungkan dua lapisan untuk membuat kelas fitur keluaran baru yang berisi informasi dari kedua input (Price, 2015). Model overlay melalui masingmasing peta kerentanan diantaranya peta tutupan lahan, peta iklim dan peta jenis tanah yang telah dibuat kemudian dilakukan overlay berdasarkan skor dan bobot masing-masing peta untuk menghasilkan peta kerentanan kebakaran lahan dan hutan. 
Teknik skoring peta tutupan lahan diadaptasi dari kelas tutupan lahan oleh Rucker dalam (Sabaraji, 2005) yang terdiri atas 7 kelas tutupan lahan (tabel 1). Untuk kelas jenis tanah dan kelas curah hujan (table 2 dan 3 )

menggunakan model standar yang diterbitkan oleh Badan Nasional Penanggulangan Bencana (BNPB) Indonesia tahun 2016. Selanjutnya dengan menggunakan panduan Risiko Bencana Indonesia (RBI) yang dikembangkan oleh BNPB tahun 2016 maka kelas tutupan lahan, jenis tanah dan curah hujan diklasifikasi kedalam 3 (tiga) kelas kerentanan. Berikut adalah formulasi kerentanan kebakaran lahan dan hutan yang dimodifikasi dari RBI (BNPB, 2016).

Rentan Kebakaran $=[(0.4 *$ Skor Tutupan Lahan $)+$ $(0.3 *$ Skor Curah Hujan $)+(0.3 *$ Skor Jenis Tanah $)]$

Penentuan skor interval masing-masing indeks per jenis indikator dilakukan menggunakan nilai indeks dari kelas 1 rendah, kelas 2 sedang, kelas 3 tinggi di sajikan pada tabel 4 . Penentuan skor tiap parameter dilakukan dengan metode pengkalian antara kelas dengan bobot masing-masing kelas. Untuk kelas 1 skornya 1, kelas 2 skornya 2, dan kelas 3 skornya 3 . Sehingga kelas yang semakin tinggi menunjukkan semakin rentan terbakar.

Tabel 1. Skor Kelas Tutupan Lahan Menurut Ruecker dalam (Sabaraji, 2005)

\begin{tabular}{clc}
\hline No & \multicolumn{1}{c}{ Tutupan Lahan (40\%) } & Skor \\
\hline 1 & $\begin{array}{l}\text { Semak Belukar, Pertanian Lahan Kering } \\
\text { Primer, Pemukiman/ Transmigrasi, Sawah } \\
\text { Belukar Rawa, Hutan Lahan Kering }\end{array}$ & 1 \\
2 & $\begin{array}{l}\text { Sekunder, Hutan Tanaman Industri, } \\
\text { Pertanian Lahan Kering, Semak }\end{array}$ & 2 \\
3 & $\begin{array}{l}\text { Hutan Rawa Sekunder, Perkebunan } \\
4\end{array}$ & 3 \\
5 & $\begin{array}{l}\text { Hutan Lahan Kering Primer, Hutan Rawa } \\
\text { Hutan Mangrove Sekunder }\end{array}$ & 4 \\
7 & $\begin{array}{l}\text { Hutan Mangrove Primer, Pertambangan } \\
\text { Tambak, Tanah Terbuka, Bandara, Rawa, }\end{array}$ & 5 \\
\hline
\end{tabular}

Tabel 2. Skor Kelas Curah Hujan (mm/ tahun)

\begin{tabular}{clcl}
\hline No & \multicolumn{1}{c}{ Curah Hujan (30\%) } & Skor & Keterangan \\
\hline 1 & $<1500 \mathrm{~mm} /$ Tahun & 3 & Kemarau \\
2 & $1500-3000 \mathrm{~mm} /$ Tahun & 2 & Penghujan- \\
3 & $>3000 \mathrm{~mm} /$ Tahun & 1 & Penarau \\
\hline
\end{tabular}

Tabel 3. Skor Kelas Jenis Tanah

\begin{tabular}{clcc}
\hline No & Jenis Tanah (30\%) & Skor & Keterangan \\
\hline 1 & Organik/ Gambut & 3 & \\
2 & Semi Organik & 2 & \\
3 & Non Organik/ Mineral & 1 & \\
\hline
\end{tabular}

Hasil analisis kerentanan diperoleh dari hasil penggabungan masing-masing skor kerentanan dengan menggunakan bobot masing-masing komponen kerentanan yang menghasilkan 3 (tiga) kelas interval kerentanan kebakaran.
Tabel 4. Kelas Kerentanan Kebakaran

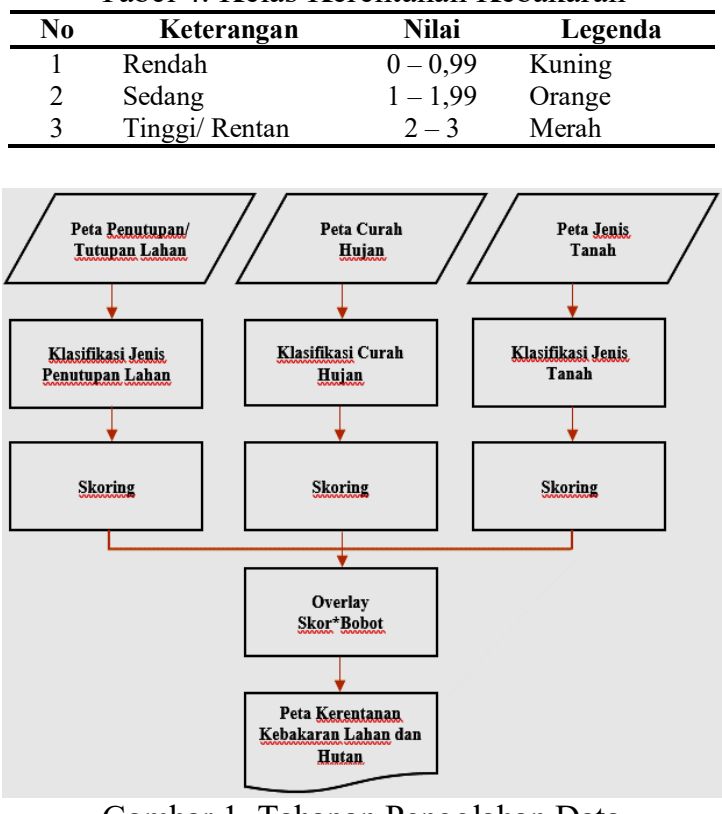

Gambar 1. Tahapan Pengolahan Data

\section{HASIL DAN PEMBAHASAN}

Peta kerentanan merupakan hasil tumpang susun (overlay) masing-masing komponen kerentanan diantaranya peta tutupan lahan, curah hujan dan peta jenis tanah. Dengan berdasarkan pada masing-masing bobot per indikator kerentanan kebakaran, yakni skor tutupan lahan, skor jenis tanah dan skor curah hujan. Untuk klasifikasi jenis tanah di Kecamatan Malifut merupakan jenis tanah non organik/ tanah mineral yang meliputi jenis tanah dystropepts seluas $32,583.82$ ha $(89.53 \%)$, hydraquents seluas $1,641.87$ ha (4.51\%), tropaquepts seluas $2,106.28$ ha $(5.78 \%)$, dan jenis tanah tropopsamment seluas 59.50 ha $(0.16 \%)$. Untuk kondisi iklim, kecamatan Malifut dipengaruh iklim laut tropis. Lokasi ini diklasifikasikan sebagai Af berdasarkan Köppen dan Geiger. Suhu rata-rata tahunan adalah $26.3{ }^{\circ} \mathrm{C}$. November adalah bulan terhangat sepanjang tahun dimana suhu rata-rata 26.9 ${ }^{\circ} \mathrm{C}$. Suhu terendah dalam setahun terlihat di bulan maret, suhu bulan ini berkisar $25.9{ }^{\circ} \mathrm{C}$. Terdapat perbedaan dalam $139 \mathrm{~mm}$ dari presipitasi antara bulan terkering dan bulan terbasah. Variasi suhu sepanjang tahun adalah $1.0^{\circ} \mathrm{C}$. Dalam setahun, curah hujan ratarata berkisar 1500 - $2000 \mathrm{~mm}$. Bulan terkering terjadi pada oktober dengan kisaran $128 \mathrm{~mm}$ hujan. Presipitasi paling besar terlihat pada bulan mei dengan rata-rata $246 \mathrm{~mm}$.

Sebaran tutupan lahan pada wilayah penelitian disesuaikan dengan klasifikasi tutupan lahan Ruecker ditampilkan pada tabel 6. Untuk itu, pada tabel 5 dapat diketahui bahwa terdapat sembilan (9) jenis penutupan lahan yang ada di Kecamatan Malifut dengan masing-masing luas penutupan lahan yang berbeda-beda. Hutan produksi merupakan penutupan lahan yang paling luas dengan persentase sebesar 
$40.10 \%$ diikuti beberapa jenis tutupan lahan yakni pertanian lahan kering sebesar $25.40 \%$, hutan lahan kering sekunder sebesar $18.29 \%$ dan semak belukar $11.12 \%$.

Jenis pepohonan yang paling umum dijumpai di kawasan hutan produksi adalah kayu gofasa (Vitex Cofassus) dengan tinggi rata-rata antara 20 hingga 25 meter. Pemanfaatan kayu inipun cukup beragam mulai dari kayu bakar untuk kebutuhan rumah tangga, pembuatan perkakas seperti meja dan tempat duduk, konstruksi rumah, dan juga ekspor. Untuk pertanian lahan kering dan hutan lahan kering sekunder umumnya merupakan area hutan adat suku Pagu dan dipergunakan sebagai lahan perkebunan. Tanaman perkebunan yang mendominasi di area ini adalah cengkeh, pala, kopi, kelapa, ubi kayu, dan juga tanaman pangan lainnya. Dengan kondisi pembukaan serta pemanfaatan lahan dan hutan yang bervariasi secara luas berimplikasi pada rentan terjadinya kebakaran. Jenis-jenis penutupan lahan yang lebih detail dapat dilihat pada tabel berikut.

Tabel 5. Jenis Penutupan Lahan Kecamatan Malifut tahun 2016

\begin{tabular}{|c|c|c|c|}
\hline No & $\begin{array}{c}\text { Jenis Penutupan } \\
\text { Lahan }\end{array}$ & $\begin{array}{l}\text { Luas } \\
\text { (Ha) }\end{array}$ & Persentase \\
\hline 1 & Hutan Produksi & $14,084.8$ & 40.10 \\
\hline 2 & $\begin{array}{l}\text { Pertanian Lahan } \\
\text { Kering }\end{array}$ & $8,923.5$ & 25.40 \\
\hline 3 & $\begin{array}{l}\text { Hutan Lahan } \\
\text { Kering Sekunder }\end{array}$ & $6,426.0$ & 18.29 \\
\hline 4 & Semak Belukar & $3,907.1$ & 11.12 \\
\hline 5 & $\begin{array}{l}\text { Hutan Mangrove } \\
\text { Primer }\end{array}$ & $1,039.7$ & 2.96 \\
\hline 6 & Permukiman & 497.0 & 1.41 \\
\hline 7 & $\begin{array}{l}\text { Hutan Mangrove } \\
\text { Sekunder }\end{array}$ & 95.3 & 0.27 \\
\hline 8 & Tanah Terbuka & 78.7 & 0.22 \\
\hline \multirow[t]{2}{*}{9} & Belukar Rawa & 70.1 & 0.19 \\
\hline & Luas Total & $35,122.2$ & \\
\hline
\end{tabular}

Hasil pemetaan kerentanan yang disajikan pada hasil penelitian ini merupakan output dari analisis menggunakan ArcGIS 10.1 yang meliputi digitasi dan perkalian antara skor dan bobot masing-masing parameter. Sebelum memasuki kelas tutupan lahan, perlu diketahui terlebih dahulu hasil reklasifikasi kelas masing-masing jenis tutupan lahan berdasarkan pada kondisi tutupan lahan di wilayah penelitian. Terdapat 7 (tujuh) kelas tutupan lahan yang diajukan (tabel 1), kelas tutupan lahan ini kemudian direklasifikasi menjadi 3 kelas berdasarkan skor jenis tutupan lahan dengan mengacu pada kriteria penentuan skor kelas yang dikembangkan dalam Indeks Risiko Bencana Indonesia oleh BNPB. Dengan demikian, semakin tinggi skor jenis tutupan lahan maka semakin rentan terjadi kebakaran. Untuk itu, jenis tutupan lahan dapat diklasifikasikan seperti berikut.
Tabel 6. Reklasifikasi Skor Jenis Tutupan Lahan Berdasarkan Skor Tutupan Lahan

\begin{tabular}{clc}
\hline No & \multicolumn{1}{c}{ Hasil Reklasifikasi } & Skor \\
\hline 1 & Semak/ Belukar, Pemukiman & 3 \\
2 & Hutan Lahan Kering Sekunder, Belukar & 3 \\
3 & Rawa, Pertanian Lahan Kering & 2 \\
4 & Hutan Produksi & 2 \\
5 & Hutan Mangrove Sekunder & 1 \\
6 & Tanah Terbuka/ Kosong & 1 \\
\hline
\end{tabular}

Hasil pemetaan kerentanan kebakaran lahan dan hutan pada gambar 2 memperlihatkan bahwa sebagian besar wilayah Kecamatan Malifut berada pada status kerentanan kebakaran sedang dan tinggi yang mendominasi seluruh kawasan hutan dan lahan Kecamatan Malifut. Untuk kerentanan kebakaran rendah sebagian besar tersebar mengikuti arah garis pantai. Jenis tutupan lahan yang ditemui pada kelas kerentanan rendah merupakan jenis hutan mangrove sekunder dan tanah terbuka atau tanah kosong. Untuk kelas kerentanan kebakaran sedang dimana hutan produksi merupakan yang paling luas kemudian disusul jenis tutupan lahan hutan lahan kering sekunder, hutan mangrove sekunder dan pertanian lahan kering. Berikutnya adalah kerentanan kebakaran lahan kelas tinggi, dimana pertanian lahan kering, hutan lahan kering sekunder, semak/ belukar dan hutan produksi mendominasi luas kelas kerentanan kebakaran, kemudian disusul ada pemukiman dan belukar rawa dengan masing-masing luasan kerentanan kebakaran.

Gambar 2 merupakan hasil pemodelan kelas kerentanan kebakaran lahan dan hutan dan untuk mengetahui sebaran kelas kerentanan kebakaran berdasarkan kondisi masing-masing jenis tutupan lahan dapat dilihat pada table 7 .

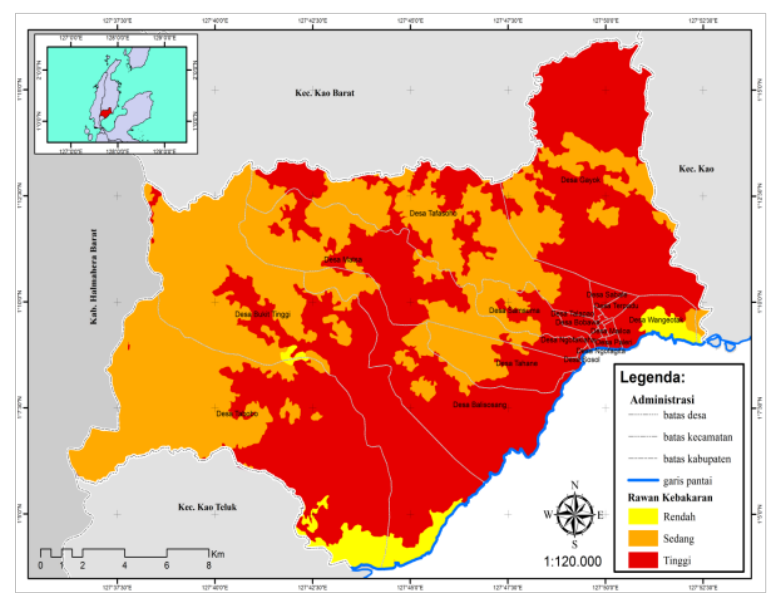

Gambar 2. Hasil Zonasi Kerentanan Kebakaran

Lahan dan Hutan Kecamatan Malifut tahun 2018.

Kerentanan kebakaran lahan dan hutan merupakan kondisi eksisting dari status kawasan. Status kawasan hutan yang mengalami perubahan menjadi komponen inti bagaimana area lahan dan hutan digunakan yang sekaligus memperlihatkan perilaku status kawasan. Perubahan status kawasan 
hutan yang merupakan bagian dari alih fungsi lahan adalah jaminan dari kerentanan kebakaran. Hasil analisis spasial pada gambar 2 memperlihatkan wilayah seluas $20,401.9$ ha $(58.08 \%)$ berada pada tingkat kerentanan kebakaran tinggi/ rentan, seluas $13,601.9$ ha $(38.72 \%)$ berada pada tingkat kerentanan kebakaran sedang, dan wilayah seluas $1,118.4$ ha $(3.18 \%)$ berada pada tingkat kerentanan kebakaran rendah. Lebih jelasnya dapat dilihat pada tabel berikut.

Tabel 7. Luas Kelas Kerentanan Kebakaran Berdasarkan Jenis Tutupan Lahan

\begin{tabular}{lccc}
\hline \multirow{2}{*}{\begin{tabular}{c}
\multicolumn{1}{c}{ Jenis Tutupan } \\
Lahan
\end{tabular}} & \multicolumn{3}{c}{ Tingkat Kerentanan Kebakaran } \\
\cline { 2 - 4 } & Rendah & Sedang & Tinggi \\
\cline { 2 - 4 } $\begin{array}{l}\text { Hutan Lahan Kering } \\
\text { Sekunder }\end{array}$ & - & $1,014.9$ & $5,411.1$ \\
$\begin{array}{l}\text { Hutan Mangrove } \\
\text { Primer }\end{array}$ & $1,039.7$ & - & - \\
Hutan Mangrove & - & 95.3 & - \\
$\begin{array}{l}\text { Sekunder } \\
\text { Hutan Produksi } \\
\text { Pertanian Lahan }\end{array}$ & - & $10,772.4$ & $3,312.4$ \\
Kering & - & $1,719.3$ & $7,204.2$ \\
$\begin{array}{l}\text { Semak/ Belukar } \\
\text { Belukar Rawa }\end{array}$ & - & - & $3,907.1$ \\
Tanah Terbuka & - & - & 70.1 \\
Pemukiman & 78.7 & - & - \\
\hline \multicolumn{1}{c}{ Jumlah (Luas) } & $1,118.4$ & $13,601.9$ & $20,401.9$ \\
\hline \multicolumn{1}{c}{$\%$} & 3.18 & 38.72 & 58.08 \\
\hline
\end{tabular}

Tabel distribusi kelas kerentanan kebakaran lahan dan hutan di kecamatan Malifut pada status kerentanan rendah mendominasi di kawasan hutan mangrove primer dan lahan terbuka dengan persentase luas areal hutan mangrove primer sebesar $1,039.7$ ha $(2.96 \%)$ dan tanah terbuka sebesar 78.7 ha $(0.22 \%)$. Untuk kerentanan kebakaran sedang sebagian besar terjadi pada kawasan hutan produksi seluas 10,772.4 ha (30.67\%) dari total luas areal hutan produksi. Selain hutan produksi, masing-masing jenis tutupan lahan juga masuk dalam kelas kerentanan sedang diantaranya hutan mangrove sekunder, hutan lahan kering sekunder dan pertanian lahan kering, dimana hutan mangrove sekunder menyumbang sebesar 95.3 ha $(0.27 \%)$, hutan lahan kering sekunder sebesar $1,014.9$ ha $(2.88 \%)$, dan pertanian lahan kering sebesar $1,719.3$ ha $(4.89 \%)$ dari total luas area hutan dan lahan Kecamatan Malifut.

Selain kerentanan kebakaran rendah dan sedang, kelas kerentanan kebakaran yang berstatus tinggi juga mencakup area seluas 20,401.9 ha atau dengan persentase kerentanan tinggi sebesar 58.08\%. Jika dipilah berdasarkan jenis tutupan lahan maka didalamnya terdapat hutan lahan kering sekunder sebesar 5,411.1 ha $(15.40 \%)$, hutan produksi sebesar $3,312.4$ ha $(9.43 \%)$, pertanian lahan kering sebesar 7,204.2 ha (20.51\%), semak belukar sebesar 3,907.1 ha $(11.12 \%)$, belukar rawa sebesar 70.1 ha $(0.19 \%)$, dan pemukiman sebesar 497 ha (1.41\%) dari total luas areal lahan dan hutan Kecamatan Malifut.
Kelas kerentanan kebakaran sedang terlihat mencapai angka $30.67 \%$ yang meliputi hampir seluruh kawasan hutan produksi dikarenakan perubahan status fungsi kawasan ini dari hutan lindung dan hutan adat Suku Pagu ke hutan produksi untuk digunakan sebagai area eksplorasi dan produksi pertambangan emas sejak tahun 2005. Perubahan area hutan produksi ini semakin meluas dari tahun ke tahun seiring perubahan luas konktrak karya perusahaan dengan pemerintah. Begitu juga dengan status kerentanan tinggi pada hutan lahan kering sekunder yang mencapai $15.40 \%$ dan pertanian lahan kering dengan persentase luasan sebesar $20.51 \%$. Hutan lahan kering sekunder sebelum perubahan merupakan kawasan hutan alam dan sebagian hutan adat yang tidak digunakan sebagai lahan perkebunan. Namun, sejak peralihan dan perubahan fungsi kawasan lahan dan hutan maka masyarakat harus melakukan perubahan penggunaan lahan dan hutan dari hutan adat dan hutan alam ke pertanian lahan kering serta hutan lahan kering sekunder.

Sebaran kerentanan kebakaran yang sangat luas mulai dari kelas sedang hingga tinggi pada masingmasing jenis tutupan lahan merupakan dampak dari kondisi perubahan penggunaan atau alih fungsi lahan. Lahan yang kecenderungan dijadikan kawasan pertanian dan perkebunan atau kawasan produksi secara langsung mendorong indeks kerentanan kebakaran semakin tinggi. Seperti yang dinyatakan oleh Harisson, et al. (2009) dalam (Mapilata, Gandasasmita, \& Djajakirana, 2013) bahwa kombinasi aktivitas manusia berupa deforestasi, perubahan tutupan lahan, pertambahan penduduk dan efek dari penyimpangan iklim (el nino) meningkatkan kejadian kebakaran hutan dan lahan.

Hutan lahan kering sekunder, pertanian lahan kering dan hutan produksi merupakan jenis tutupan lahan yang paling luas di kecamatan Malifut dengan masing-masing total luasan sebesar 6,426 ha (Hutan lahan kering sekunder), 8,923.5 ha (pertanian lahan kering), dan $14,084.8$ ha (hutan produksi). Penelitian dilakukan oleh (Jawad, Nurdjali, \& Widiastuti, 2015) bahwa terjadi perubahan penutupan lahan dari vegetasi yang sulit terbakar menjadi vegetasi yang lebih peka atau mudah terbakar yang disebabkan oleh pembukaan areal perkebunan dan aktivitas manusia. Dengan demikian, perubahan jenis tutupan lahan secara nyata mengambil bagian penting dalam mengontrol indeks kerentanan kebakaran lahan dan hutan satu kawasan. Sehingga perubahan jenis tutupan lahan yang cenderung lebih dinamis dari suatu sistem lahan dapat menentukan tingkat kerentanan kebakaran lahan tersebut.

\subsection{Pencegahan Kerentanan Kebakaran Lahan dan Hutan}

Penetapan fungsi kawasan lahan dan hutan berdasarkan indikator jenis bencana merupakan hal mendasar yang perlu dipertimbangkan terutama peran pemerintah setempat dalam menetapkan 
kembali secara detail mengenai kemampuan serta fungsi kawasan lahan dan hutan tersebut. Penetapan fungsi kawasan lahan dan hutan merupakan langkah praktis dalam menekan indeks kerentanan kebakaran dalam jangka panjang. Selain itu, tahap penyuluhan maupun edukasi mengenai dampak perubahan lahan kepada masyarakat adalah hal pokok yang harus diupayakan. Sebab bagaimanapun duduk perkara perubahan lahan adalah tentang seberapa tegas kebijakan yang diusulkan pemerintah terutama dalam hal rencana aksi strategi penanggulangan bencana di tingkat lokal yang kemudian dipahami oleh masyarakat terutama soal dampak bencana dimasa depan.

Aktivitas pertanian yang muncul dalam masyarakat mencakup pemanfaatan lahan yang didalamnya ada persiapan hingga pembukaan lahan, sebagai tanda kepemilikan pribadi metode klasik yang digunakan adalah dengan cara membakar, hal ini tentu dapat dilakukan secara terkendali dengan berbagai pengawasan dari semua elemen terkait.

\section{KESIMPULAN}

Kerentanan kebakaran lahan dan hutan di Kecamatan Malifut berada pada tiga kelas kerentanan, dimana tiap kelas memiliki luas yang berbeda-beda, pada kelas kerentanan kebakaran rendah seluas $1,118.4$ ha atau $3.18 \%$ yang meliputi hutan mangrove primer dan tanah terbuka. Kerentanan kebakaran lahan sedang meliputi area seluas $13,601.9$ ha atau $38.72 \%$ yang mencakup sebagian besar hutan produksi, serta diikuti pertanian lahan kering, hutan mangrove sekunder dan hutan lahan kering sekunder. Untuk kelas kerentanan kebakaran tinggi merupakan yang terluas mencakup area seluas 20,401.9 ha atau 58.08\% dari total luas kawasan lahan dan hutan Kecamatan Malifut. Tutupan lahan yang berada pada kelas kerentanan kebakaran tinggi sebagian besar berasal dari hutan lahan kering sekunder, pertanian lahan kering, hutan produksi, semak belukar. Kemudian diikuti oleh belukar rawa dan pemukiman.

Dampak perubahan tutupan lahan sangat rentan terjadinya kebakaran, untuk itulah mengevaluasi kembali jenis tutupan lahan berdasarkan indikator kemampuan lahan merupakan salah satu langkah taktis untuk menghindari wilayah rentan terbakar yang semakin meluas.

Bagaimanapun, penelitian ini masih berada pada kajian yang sempit dan terbatas pada kondisi fisik lokasi, untuk itu, kedepannya pendalaman kajian serta kompleksitas adalah inti yang perlu digali lebih dalam terutama soal kerentanan kebakaran lahan dan hutan yang juga memuat kondisi sosial dan ekonomi masyarakat, sebab masyarakat adalah subjek utama untuk membangun desa tangguh bencana dimasa depan yang lebih baik.

\section{DAFTAR PUSTAKA}

AHMED, Z., KRUPNIK, T., \& KAMAL, M. (2018). Introduction to basic GIS and spatial analysis using QGIS: Applications in Bangladesh. Dhaka, Bangladesh: Cereal Systems Initiative for South Asia (CSISA) and The International Maize and Wheat Improvement Center, CIMMYT.

AJIN, R., LOGHIN, A.-M., VINOD, P., \& JACOB, M. (2016). Forest Fire Risk Zone Mapping Using RS and GIS Techniques: A Study in Achankovil Forest Division, Kerala, India. Journal of Earth, Environment and Health Sciences, 2(3), 109 - 115.

ARIFIN, Z. (2010). Pola Spasial Kerentanan Bencana Alam (Studi Kasus Kabupaten Cianjur). Universitas Indonesia, Fakultas Matematika dan Ilmu Pengetahuan Alam. Depok: Not Publish

BAPEDA PROVINSI YOGYAKARTA. (2008). Metode Pemetaan Risiko Bencana Provinsi Daerah Istimewa Yogyakarta. Yogyakarta: Early Recovery Assistance, Bappenas, Bapeda Yogyakarta, dan UNDP.

BERNARD, B., EMMANUEL, O., \& MUGANGA, P. (2017). GIS Application in Agricultural Development (2017); Training Manual Based on QGIS Software (version 2.18.3). International Fund of Agricultural Development (IFAD).

BNPB. (2016). Risiko Bencana Indonesia. Jakarta: Badan Nasional Penanggulangan Bencana Indonesia.

CROWARDS, T. (2000). Comparative Vulnerability to Natural Disasters in the Caribbean. Vulnerability Assessment Techniques (pp. 1 - 30). North Carolina: Caribbean Development Bank.

CUTTER, S. L. (2013). Vulnerability to Environmental Hazard. Progres In Human Geography, 20(4), 529 - 539.

CUTTER, S. L., BORUFF, B. J., \& SHIRLEY, W. L. (2003). Social Vulnerability to Environmental Hazard. Social Science Quarterly, 84(2), $242-261$.

DARMAWAN, M., ANIYA, Y., \& TSUYUKI, S. (2001). Forest Fire Hazard Model Using Remote Sensing and Geographic Information Systems: Toward understanding of Land and Forest Degradation in Lowland areas of East Kalimantan, Indonesia. Asian Conference on Remote Sensing, (pp. 1 - 6). Singapore.

ESRI. (2016). The ArcGIS Imagery Book. (C. Brown, \& C. Harder, Eds.) California: ESRI Press.

GAITHER, C. J., POUDYAL, N. C., GOODRIC, S., BOWKER, J. M., MALONE, S., \& GAN, J. 
566 Jurnal Teknologi Informasi dan Ilmu Komputer (JTIIK), Vol. 6, No. 5, Oktober 2019, hlm. 559-566

(2011). Wildland fire risk and social vulnerability in the Southeastern United States: An exploratory spatial data analysis approach. Forest Policy and Economics, 13, $24-36$.

GARBUTTA, K., ELLULB, C., \& FUJIYAMAB, T. (2015). Mapping social vulnerability to flood hazard in Norfolk, England. Environmental Hazards, 14(2), 156 - 186.

GLAUBER, A. J., MOYER, S., ADRIANI, M., \& GUNAWAN, I. (2016). Kerugian dari Kebakaran Hutan: Analisis Dampak Ekonomi Dari Krisis Kebakaran Tahun 2015. Laporan Pengetahuan Lanskap Berkelanjutan Indonesia. Jakarta: World Bank dan Bursa Efek Indonesia.

HAPSORO, A., \& BUCHORI, I. (2015). Kajian Kerentanan Sosial Dan Ekonomi Terhadap Bencana Banjir (Studi Kasus: Wilayah Pesisir Kota Pekalongan). Tekhnik Perencanaan Wilayah dan Kota, 4(4), 542 553.

JAWAD, A., NURDJALI, B., \& WIDIASTUTI, T. (2015). Zonasi Daerah Rawan Kebakaran Hutan dan Lahan di Kabpaten Kubu Raya Provinsi Kalimantan Barat. Jurnal Hutan Lestari, 3(1), 88 - 97.

LAGRO, J. (2005). Spatial Information and Mapping. Retrieved from Geographic Information System: https://www.sciencedirect.com/topics/earth -and-planetary-sciences/geographicinformation-system

MAPILATA, E., GANDASASMITA, K., \& DJAJAKIRANA, G. (2013). Analisis Daerah Rawan Kebakaran Hutan dan Lahan Dalam Penataan Ruang di Kota Palangka Raya Provinsi Kalimantan Tengah. Globe, 15(2), 178 - 184.

MULDER, M., WHITE, J., ALVAREZ, F., HAN, T., ROGAN, J., \& HAWKES, B. (2009). Characterizing Boreal Forest Wildfire with Multi-temporal Landsat and LIDAR Data. Remote Sensing of Environment, 113, 1540 1555.

NETELER, M., \& MITASOVA, H. (2008). OPEN SOURCE GIS. A GRASS GIS Approach. Third Edition. New York: Springer.

PRICE, M. H. (2015). Mastering ArcGIS. Seventh Edition. New York: McGraw Hill Education.

RAHAYU, Y., MULUD, K., \& HIJRIANI, A. (2016). Pemetaan Penyebaran dan Prediksi Jumlah Penduduk Menggunakan Model Geometrik di Wilayah Bandar Lampung Berbasis Web-GIS. Journal of Information Systems Engineering and Business Intelligence, 2(2), 95 - 101.
SABARAJI, A. (2005). Identifikasi Zone Rawan Kebakaran Hutan dan Lahan dengan Aplikasi SIG di Kabupaten Kutai Timur. Samarinda: Universitas Mulawarman.

SISWOYO, B. (2007). Hutan Rakyat dan Serbuan Pasar: Studi Refleksi Pengusahaan Hutan Rakyat Lestari secara Kolaboratif di Pacitan, ]awa Timur. Jurnal Ilmu Sosial dan Ilmu Politik, 11(2), 153 - 286.

SLETNES, A. I. (2010). Assessment of Forest Fire Risks and Innovative Strategies for Fire Prevention. Ministerial Conference on the Protection of Forests in Europe, (pp. 1 - 46). Rhodes, Greece.

SOLICHIN, TARIGAN, L., KIMMAN, P., FIRMAN, B., \& BAGYONO, R. (2007). Pemetaan Daerah Rawan Kebakaran: South Sumatra Forest Fire Management Project. Sumatera Selatan: Dinas Kehutanan Provinsi Sumatera Selatan dan Balai Pemantapan Kawasan Hutan Wilayah II.

SUDIBYAKTO. (2003, Maret). Anomali Iklim dan Mitigasi Kebakaran Hutan di Indonesia. Majalah Geografi Indonesia, 17(1), 71 - 80.

SUGIARTO, D., GANDASASMITA, K., \& LAILAN. (2013). Analisis Risiko Kebakaran Hutan dan Lahan di Taman Nasional Rawa Aopa Watumohai dengan Pemanfaatan Pemodelan Spasial. Globe, $15(1), 62-67$.

SUGIHARTO, A. (2015). Kerentanan, Strategi Nafkah, dan Tingkat Kesejahteraan Keluarga Petani di Kecamatan Playen Kabupaten Gunungkidul. Tesis, Institut Pertanian Bogor, Sekolah Pascasarjana, Bogor.

TARIGAN, M., NUGROHO, D., FIRMAN, B., \& KUNARSO, A. (2016). Pemutakhiran Peta Rawan Kebakaran Hutan dan Lahan di Provinsi Sumatera Selatan Tahun 2015. Dokumen Standar Operasional Prosedur untuk Pelaksanaan dan Pengelolaan Jaringan Data Spasial Kehutanan di Provinsi Sumatera Selatan. Palembang: Dinas Kehutanan Provinsi Sumatera Selatan, GIZ Biodiversity and Climate Change (BIOCLIME).

WENG, Q. (2010). Remote Sensing and GIS Integration. Theories, Methods, and Applications. New York: McGraw-Hill Companies.

WIDODO, R. B. (2014). Pemodelan Spasial Resiko Kebakaran Hutan (Studi Kasus Provinsi Jambi, Sumatera). Pembangunan Wilayah dan Kota, 10(2), $127-138$. 